\title{
Measuring the Added Effectiveness of Using Detailed Spatial and Temporal Data in Generating Accessibility Measures
}

\author{
Boer Cui, Emily Grisé ${ }^{\dagger}$, Anson Stewart ${ }^{\ddagger}$, Ahmed El-Geneidy ${ }^{\star \star}$ \\ Keywords: public transport, commute duration, mode share, accessibility measures \\ https://doi.org/10.32866/9736 \\ Transport Findings
}

It is hypothesized that spatially disaggregated and temporally variable data will lead to more accurate determinations of accessibility. This paper examines whether such measures are more effective in predicting public transport mode share and commute duration in Montreal, Canada through regression models. While results show that the model fit to predict mode share is better when accessibility is generated using detailed spatial and temporal data, the improvement is minimal. In predicting commute duration, no improvements are observed. Furthermore, the change in resulting values of accessibility between measures is observable and varies depending on the configuration and frequency of transport supply.

\section{RESEARCH QUESTION AND HYPOTHESES}

A current trend among researchers is the pursuit of more complex approaches to measure accessibility (Geurs, Krizek, and Reggiani 2012), some focusing on time-sensitive components, i.e., variations in transit service (Boisjoly and El-Geneidy 2016; Conway, Byrd, and van der Linden 2017; Farber and Fu 2017; Stepniak et al. 2019), while others aim to minimize errors that arise due to spatial aggregation (Apparicio et al. 2017; Hewko, Smoyer-Tomic, and Hodgson 2002). However, the effectiveness of these resource-heavy approaches remains to be reviewed.

Our research examines differences between three accessibility measures, two generated using the Conveyal Analysis tool (Github 2018); both of which use fine-grained spatial units of analysis, but one uses a static departure time while the other derives median travel time based on variable departures. The third is the conventional approach evaluated at census tract (CT) level and uses a static departure time. The impacts of the three accessibility measures are compared in a series of mode share as well as commute duration regression models.

\section{METHODS AND DATA}

The three accessibility measures are referred to as (a) Conventional; (b) Detailed 8 a.m.; and (c) Detailed 7-9 a.m. and are cumulative-opportunity measures. Data inputs include number of jobs available at CT level as well as the General

\footnotetext{
* Civil Engineering, McGill University Link: http://tram.mcgill.ca/About/ahmed/ahmed.html

† School of Urban Planning, University of Alberta Link: https://www.ualberta.ca/earth-sciences/urban-regional-planning/ about-the-program/research

‡ Conveyal Link: https://www.conveyal.com

** Urban Planning, McGill University ORCID iD: 0000-0002-0942-4016 Link: http://tram.mcgill.ca/About/ahmed/ ahmed.html
} 
Transit Feed Specification (GTFS) and street network files that are used to generate travel times between origins and destinations for the specified spatial and temporal unit of analysis.

Job data is obtained from Statistics Canada 2016 Census Flow tables for the Montreal metropolitan region that represent the number of commuters, by mode of transport, commuting between pairs of CTs. Here, we consider that the sum of all jobs available at different times throughout the entire day is assumed to be available at all times. The number of jobs available in a CT is the sum of all arriving commuters and is either summarized spatially at the CT centroid in the Conventional measure or divided according to areal proportion among grid cells intersecting a given CT.

For the Conventional measure, a public transport travel time matrix (done using the Add GTFS to a Network Dataset toolbox for ArcMap) is generated with scheduled GTFS data for an 8 a.m. departure on May 16, 2017. Travel time matrices for Detailed measures are generated using Conveyal Analysis. For the Detailed 8 a.m. measure, median travel time is taken using GTFS data, based on departure times from 8:00 to 8:01 (approximately 8 a.m.) and for the Detailed 7-9 a.m. measure, median travel time is based on departure times at one-minute intervals between 7 and 9 a.m. Travel time threshold used in all measures is 50 minutes, the median travel time for all commuters in the Montreal region.

To generate the spatial level of analysis used in the Conventional measure, the $\mathrm{CT}$ and travel time between CT centroids is used to determine the number of reachable jobs. For the Detailed measures, travel time is calculated between the centroids of square raster cells (each approximately $0.05 \mathrm{~km}^{2}$ ) of a regular grid covering the study area. Then the accessibility values from the Detailed measures are aggregated to CT level (unweighted by population) to compare with the Conventional measure with zero-accessibility grid cells removed prior to aggregation. Despite this, the prevalence of very low accessibility values in outer regions could have resulted in some aggregation error in this process. A person-weighted average would be an improvement on the methodology but the population data was not available at the grid cell level.

Linear regression models were developed for percentage of commuters using public transport leaving the origin CT (assumed to be constant). Note here that there are two accessibility variables, a squared and a linear term, that enter into the models and reflect the quadratic relationship that we have described in previous research between public transport mode share and accessibility (Cui and El-Geneidy 2019). Multilevel mixed effects models developed previously by Cui et al. (2019) have been used here to model commute duration. Accessibility measures to jobs and workers at both the origin and destination CTs are generated, which accounts for the impact of competition, and are entered into the models as per the previous setup used by Cui et al. (2019) and Levinson (1998). 


\section{FINDINGS}

The percent difference in accessibility at CT level between Detailed and Conventional measures are shown in Figure 1. We observe that differences between Detailed and Conventional measures are minimal with some decreases in the accessibility values generated using the Detailed measures compared to the Conventional measure in the central area and more significant changes at the tips of the Island of Montreal. In general, there are more instances of decreases than increases observed for areas off the island, which may be explained by the use of aggregated average accessibility, which is sensitive to very low values, resulting in lower accessibility values using Detailed measures. In addition, significant increases are observed in some suburban CTs served directly by commuter trains.

In Figure 2, areas of increases and decreases are observed across the region, which could be related to the frequency and timing of transit service in these areas. For example, when departure times align with transit service at 8 a.m. (i.e., commuters arrive just in time for the service at 8 a.m.), use of variable departure times would not improve accessibility especially if service is infrequent and long wait times are observed. Similarly, the radial pattern of the change in accessibility (i.e., the percentage of increase in accessibility is highest at the center and then decreases in places further away, after which the increase becomes a decrease even further from the center), is also emphasized by infrequent service, where areas at certain distances from stations are penalized when variable departure times are considered due to lack of coordination between access times and scheduled service.

Results of regression models for mode share and commute duration are shown in Tables 1 and 2, respectively. The $\mathrm{R}^{2}$ value of the mode share models is highest using the Detailed 7-9 a.m. measure but relative improvement is minimal at $1.3 \%$. Also, we observe in Table 1 that coefficients of accessibility variables increase in magnitude as more-detailed data is used in accessibility measures, similar to results from Owen and Levinson (2015) . It seems that more-detailed measures are more effective in capturing the impacts of accessibility on mode share. For commute duration, Detailed measures did not improve model fit and accessibility to jobs at the origin variable is not significant when these measures are used. One limitation of the study is that spatial autocorrelation was not addressed for the mode share models whereas use of the multilevel models for commute time account, to some extent, for this factor.

Our analysis demonstrates that the use of detailed data to generate accessibility measures may improve model fit in certain analyses. In addition, the study shows that there exist substantial differences in accessibility values generated using Detailed measures and Conventional measures, particularly in areas with infrequent service. 

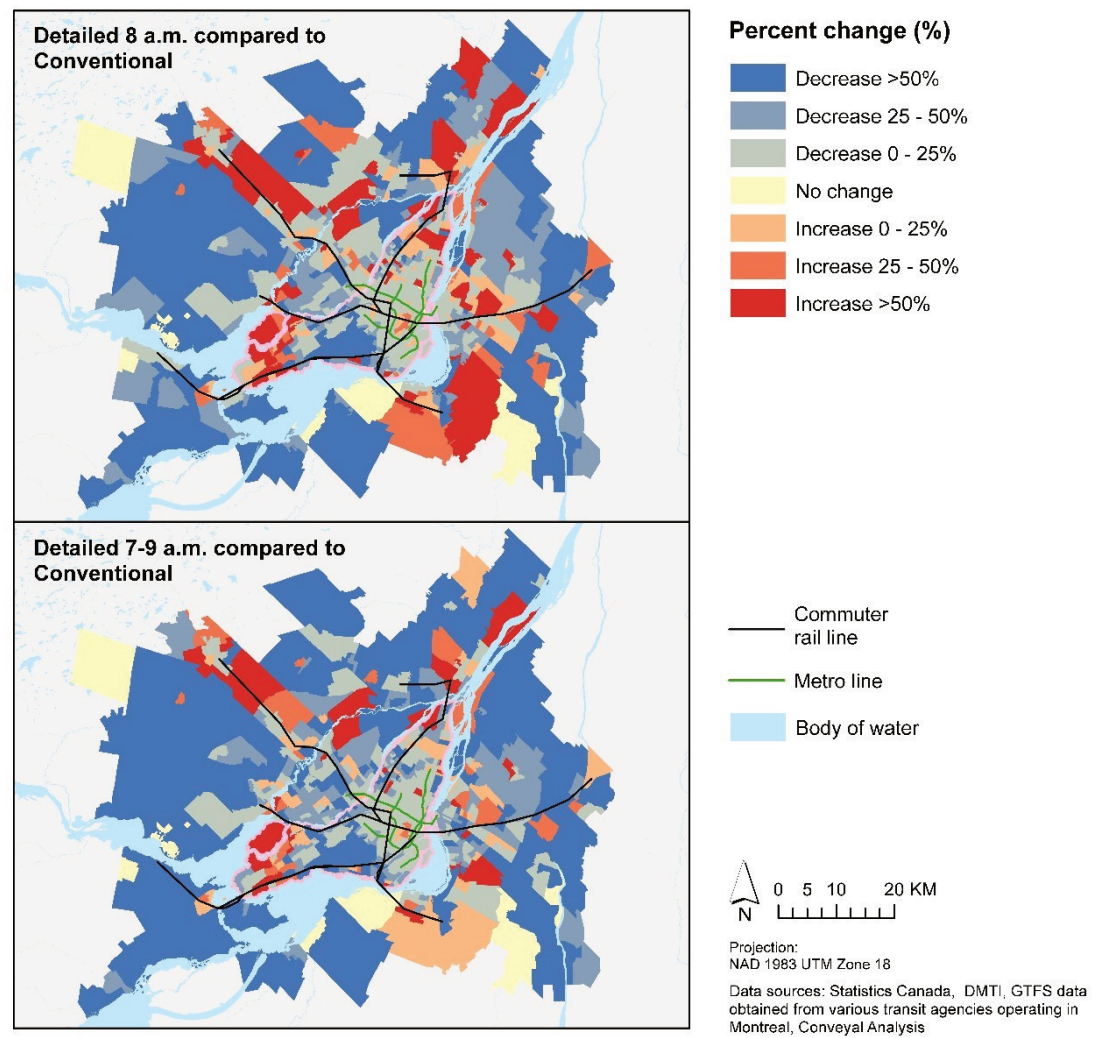

Figure 1: Comparison of the Percent Change of Accessibility Aggregated at the CT Level Between the Detailed Measures and the Conventional Measure

Note that the reference for determining percent difference is the second measure mentioned.

\section{ACKNOWLEDGMENTS}

This research was funded by the Social Sciences and Humanities Research Council of Canada (SSHRC). 


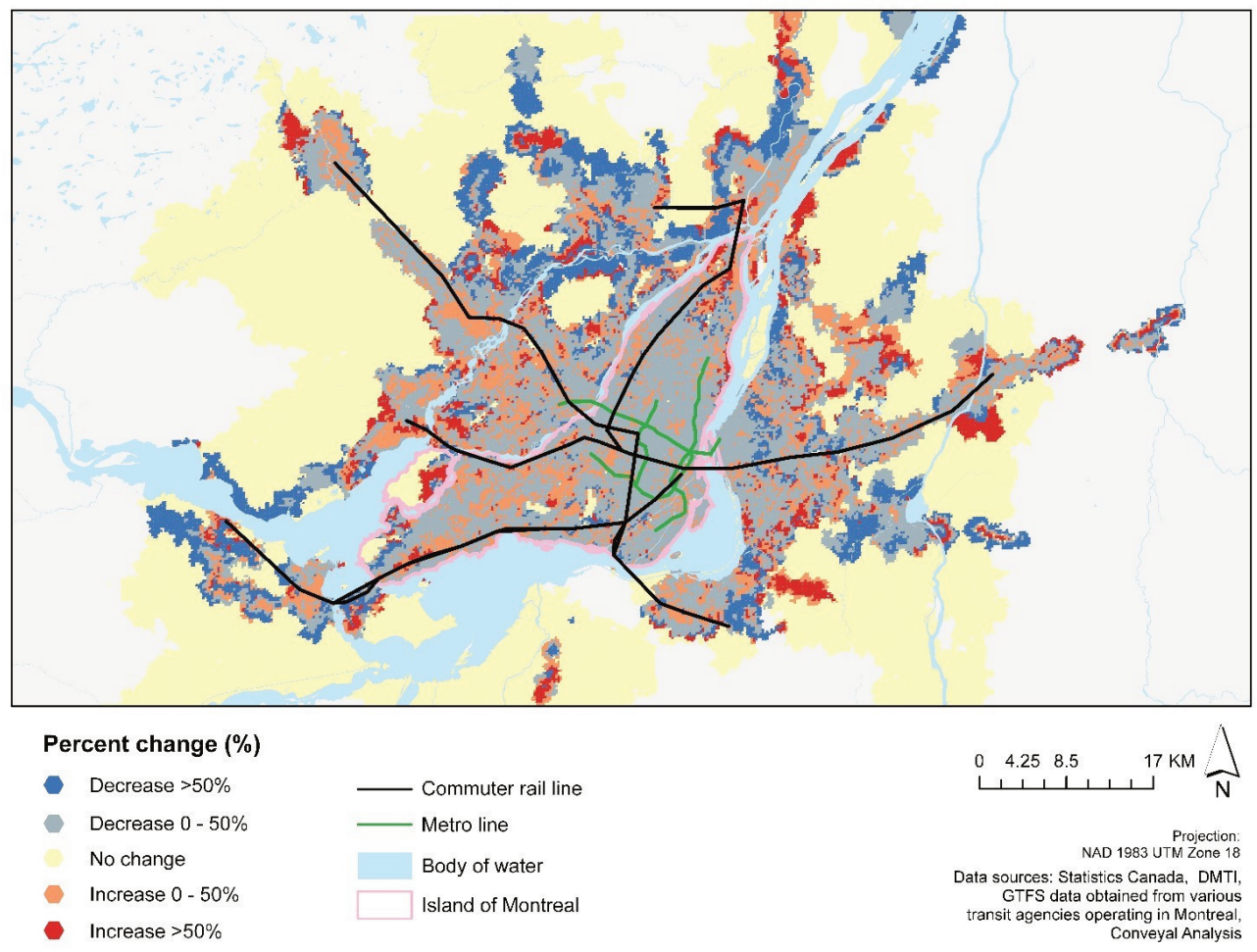

Figure 2: Comparison of the Percent Change of Accessibility at Grid Cell Centroids Between Detailed Measures (7-9 a.m. Compared to 8 a.m.) 
Table 1: Results of the Regression Models for Public Transport Mode Share for Each Measure

\begin{tabular}{|c|c|c|c|c|c|c|}
\hline & \multicolumn{2}{|c|}{ Conventional } & \multicolumn{2}{|c|}{ Detailed 8 a.m. } & \multicolumn{2}{|c|}{ Detailed 7-9 a.m. } \\
\hline & Coefficient & Signif. & Coefficient & Signif. & Coefficient & Signif. \\
\hline \multicolumn{7}{|l|}{ Accessibility Measures } \\
\hline Accessibility to jobs (\%) & 0.639 & $* * *$ & 0.862 & ${ }^{* * *}$ & 0.917 & $* * *$ \\
\hline Accessibility to jobs squared $\left(\%^{2}\right)^{a}$ & -0.005 & $* * *$ & -0.009 & $* * *$ & -0.010 & $* * *$ \\
\hline \multicolumn{7}{|l|}{ Control Variables } \\
\hline $\begin{array}{l}\text { Population density (thousand persons/ } \\
\mathrm{km}^{2} \text { ) }\end{array}$ & 0.405 & $* * *$ & 0.364 & ${ }^{* * *}$ & 0.336 & $* * *$ \\
\hline Average age & -0.206 & $* * *$ & -0.184 & $* * *$ & -0.162 & $* * *$ \\
\hline Average number of people in a household & -0.356 & & 0.050 & & 0.427 & \\
\hline Social deprivation indicator (decile) & 1.115 & $* * *$ & 1.111 & ${ }^{* * *}$ & 1.187 & $* * *$ \\
\hline $\begin{array}{l}\text { Network distance to closest rapid transit } \\
\text { station }(\mathrm{km})\end{array}$ & -0.354 & $* * *$ & -0.329 & *** & -0.339 & $* * *$ \\
\hline $\begin{array}{l}\text { Network distance to closest highway on- } \\
\operatorname{ramp}(\mathrm{km})\end{array}$ & 0.120 & & 0.088 & & 0.101 & \\
\hline Constant & 18.634 & $* * *$ & 16.451 & *** & 14.726 & $* * *$ \\
\hline $\begin{array}{l}\text { Akaike's information criterion | Bayesian } \\
\text { information criterion }\end{array}$ & \multicolumn{2}{|c|}{$6475 \mid 6514$} & \multicolumn{2}{|c|}{6434 | 6478} & \multicolumn{2}{|c|}{6432 | 6476} \\
\hline $\mathrm{R}^{2}$ & \multicolumn{2}{|c|}{0.785} & \multicolumn{2}{|c|}{0.794} & \multicolumn{2}{|c|}{0.795} \\
\hline \multicolumn{7}{|l|}{${ }^{*} \mathrm{p}<0.05^{* *} \mathrm{p}<0.01{ }^{* * *} \mathrm{p}<0.001$} \\
\hline \multicolumn{7}{|c|}{$\begin{array}{l}{ }^{a} \text { Cui and El-Geneidy (2019) found a nonlinear relationship between accessibility and mode share that is approximated using a squared accessibility term here: } \\
\text { a negative squared accessibility term and a positive linear term implies a relationship characterized by a concave parabola where increasing accessibility leads to } \\
\text { increase in mode share up until the vertex, where increasing accessibility has a negative impact on mode share. }\end{array}$} \\
\hline
\end{tabular}


Table 2: Results of the Multilevel Regression Models for Public Transport Commute Duration for Each Measure

\begin{tabular}{|c|c|c|c|c|c|c|}
\hline & \multicolumn{2}{|c|}{ Conventional } & \multicolumn{2}{|c|}{ Detailed 8 a.m. } & \multicolumn{2}{|c|}{ Detailed 7-9 a.m. } \\
\hline & Coefficient & Signif. & Coefficient & Signif. & Coefficient & Signif. \\
\hline \multicolumn{7}{|l|}{ Accessibility Measures } \\
\hline Accessibility to jobs at origin (\%) a & -0.005 & $* * *$ & -0.001 & & -0.002 & \\
\hline Accessibility to workers at origin (\%) a & -0.005 & $* *$ & -0.009 & $* * *$ & -0.009 & $* * *$ \\
\hline Accessibility to jobs at destination (\%) a & 0.003 & $* * *$ & 0.005 & $* * *$ & 0.006 & $* * *$ \\
\hline Accessibility to workers at destination (\%) a & -0.004 & $* * *$ & -0.006 & $* * *$ & -0.007 & $* * *$ \\
\hline \multicolumn{7}{|l|}{ Control Variables } \\
\hline $\begin{array}{l}\text { Median household income (thousand } \\
\text { CAD\$) }\end{array}$ & 0.001 & & 0.001 & & 0.001 & \\
\hline Average age & -0.006 & $* * *$ & -0.006 & $* * *$ & -0.007 & $* * *$ \\
\hline Average number of people in a household & -0.009 & & -0.009 & & -0.010 & \\
\hline Unemployment rate (\%) & 0.002 & & 0.002 & & 0.002 & \\
\hline $\begin{array}{l}\text { People spending }>30 \% \text { of income on } \\
\text { housing (\%) }\end{array}$ & -0.003 & $* * *$ & -0.003 & $* *$ & -0.003 & $* *$ \\
\hline Immigrants (\%) & 0.005 & $* *$ & 0.005 & * & 0.005 & * \\
\hline $\begin{array}{l}\text { People with high school degree as highest } \\
\text { level of education (\%) }\end{array}$ & -0.0004 & & -0.0004 & & 0.000 & \\
\hline $\begin{array}{l}\text { Network distance to closest heavy rail } \\
\text { transit station }(\mathrm{km})\end{array}$ & 0.027 & $* * *$ & 0.027 & $* * *$ & 0.027 & $* * *$ \\
\hline $\begin{array}{l}\text { Network distance to closest highway on- } \\
\text { ramp (km) }\end{array}$ & 0.015 & $* * *$ & 0.015 & $* * *$ & 0.015 & $* * *$ \\
\hline Network distance to city center $(\mathrm{km})$ & 0.018 & $* * *$ & 0.018 & $* * *$ & 0.018 & $* * *$ \\
\hline Constant & 3.863 & $* * *$ & 3.853 & $* * *$ & 3.865 & $* * *$ \\
\hline $\begin{array}{l}\text { Akaike's information criterion | Bayesian } \\
\text { information criterion }\end{array}$ & 477208 & 390 & $476914 \mid$ & 097 & 476705 & 887 \\
\hline Snijders/Bosker $\mathrm{R}^{2}$ Level 1 & 0.49 & & 0.4 & & 0.4 & \\
\hline Snijders/Bosker $\mathrm{R}^{2}$ Level 2 & 0.87 & & 0.86 & & 0.8 & \\
\hline \multicolumn{7}{|l|}{${ }^{*} \mathrm{p}<0.05^{* *} \mathrm{p}<0.01^{* * *} \mathrm{p}<0.001$} \\
\hline \multicolumn{7}{|c|}{$\begin{array}{l}\text { aFour accessibility measures enter into the models and the impact of the coefficients are as expected with the exception of the accessibility to workers at the origi } \\
\text { variable where one would expect that increased accessibility to workers at home would increase travel time as a sign of increased competition. At the same time } \\
\text { increased accessibility to jobs at destination increases travel time, which is expected. }\end{array}$} \\
\hline
\end{tabular}

This is an open-access article distributed under the terms of the Creative Commons Attribution 4.0

International License (CCBY-NC-4.0). View this license's legal deed at https://creativecommons.org/ licenses/by-nc/4.0 and legal code at https://creativecommons.org/licenses/by-nc/4.0/legalcode for more information. 


\section{REFERENCES}

Apparicio, P., J. Gelb, A.-S. Dubé, S. Kingham, L. Gauvin, and É. Robitaille. 2017. “The Approaches to Measuring the Potential Spatial Access to Urban Health Services Revisited: Distance Types and Aggregation-Error Issues.” International Journal of Health Geographics 16: 32.

Boisjoly, G., and A. El-Geneidy. 2016. "Daily Fluctuations in Transit and Jobs Availability: A Comparative Assessment of Time-Sensitive Accessibility Measures." Journal of Transport Geography 52: $73-81$.

Conway, M.W., A. Byrd, and M. van der Linden. 2017. "Evidence-Based Transit and Land Use Sketch Planning Using Interactive Accessibility Methods on Combined Schedule and HeadwayBased Networks." Transportation Research Record 2563: 45-53.

Cui, B., G. Boisjoly, A. El-Geneidy, and D. Levinson. 2019. "Accessibility and the Journey to Work through the Lens of Equity." Journal of Transport Geography 74: 269-77.

Cui, B., and A. El-Geneidy. 2019. Accessibility, Equity, and Mode Share: An Introductory Analysis across 11 Canadian Metropolitan Areas. Transport Findings.

Farber, S., and L. Fu. 2017. "Dynamic Public Transit Accessibility Using Travel Time Cubes: Comparing the Effects of Infrastructure (Dis)Investments over Time." Computers, Environment and Urban Systems 62: 30-40.

Geurs, K.T., K.J. Krizek, and A. Reggiani. 2012. "Accessibility Analysis and Transport Planning: An Introduction." In Accessibility Analysis and Transport Planning. Challenges for Europe and North America, edited by K.T. Geurs, K.J. Krizek, and A. Reggiani, 1-12. Northampton, England: Edward Elgar Publishing Limited.

Github. 2018. “Conveyal Analysis Release 4.5.1.” December 17, 2018. https://github.com/ conveyal/r5/releases/tag/v4.5.1.

Hewko, J., K.E. Smoyer-Tomic, and M.J. Hodgson. 2002. "Measuring Neighbourhood Spatial Accessibility to Urban Amenities: Does Aggregation Error Matter?" Environment and Planning A 34: 1185-1206.

Levinson, D.M. 1998. “Accessibility and the Journey to Work.” Journal of Transport Geography 6: $11-21$.

Owen, A., and D. Levinson. 2015. "Modeling the Commute Mode Share of Transit Using Continuous Accessibility to Jobs." Transportation Research Part A: Policy and Practice 74: 110-22.

Stepniak, M., J.P. Pritchard, K.T. Geurs, and S. Goliszek. 2019. “The Impact of Temporal Resolution on Public Transport Accessibility Measurement." Review and Case Study in Poland. Journal of Transport Geography 75: 8-24. 